\title{
Audit Culture and a Different Kind of Publishing Crisis in the Academy
}

\author{
Marc Spooner \\ University of Regina \\ Author's Note
}

This article was also published by the LSE Impact Blog, of the London School of Economics under the title, The growing, high-stakes audit culture within the academy has brought about a different kind of publishing crisis (November 5, 2018). 


\section{Audit Culture and a Different Publishing Crisis in the Academy}

By now most readers will have heard the news about the so called "Grievance Studies" affair, where a team of three writers, with the explicit goal to deceive, succeeded in getting four of 20 fraudulent research papers published and another three accepted in humanities journals. They did so, as reported in the New York Times (Schuessler, 2018), by starting with conclusions, they would work "backward to support by aping the relevant fields' methods and arguments, and sometimes inventing data." The New York Times article quotes psychologist Steven Pinker (2018) who tweeted "Is there any idea so outlandish that it won't be published in a Critical/PoMo/Identity/“Theory' journal?”

The truth is, psychology and other scientific disciplines have their own publishing crisis to worry about. High-profile cases such as the fresh resignation of Cornell food scientist Brian Wansinkor (Rosenberg, \& Wong, 2018) or the dubious p-hacking power pose research (Dominus, 2017) of the no-longer-tenure-stream Harvard Business School psychologist Amy Cuddy, reveal a widening replicability, or outright deception, crisis in the social sciences.

Sure, the "gotcha" moments, such as those reported by these hoaxers or the individual accounts of the rise and fall of fraudulent star academics, are perhaps thrilling to read about in a schadenfreude kind of way. However, the greater harm of these incidents is the further erosion of our collective trust in scientific research. They provide even more fuel to a growing and dangerous anti-intellectualism and eventually could lead to the complete mistrust of science itself.

But these distract from the bigger and, frankly, more important story happening on today's campuses, which is the growing, high-stakes audit culture within the academy that results in extreme pressures to publish and, for some, the resort to cooked-up findings and the deliberate faking of science.

The circumstances by which university professors find themselves under extreme pressure to publish and meet specific research and funding targets is what truly merits our closer attention. Necessitating our interrogation is how the publish-or-perish culture has become so alarmingly demanding that it consumes most of a scholar's time and output and drives some to dangerously high stress levels, the temptation to falsify findings, and, in some extreme cases such as that of Dr Grimm (Cassidy, 2014), to even take one's own life.

Part of the answer, it seems, lies in the manner in which academia has been perverted by audit culture all over the globe. Corporate shifts in how universities are governed have spawned a whole class of middle-management auditors (accountants, in function) who have replaced faculty administrative positions, while retaining little of those administrators' collegial academic traditions other than perhaps their holdover titles, such as associate dean, associate vice president, dean, and so on. The ballooning of the management class in the academy is directly related to its widespread shift to new public management techniques which include (a) adopting private-sector management practices; (b) introducing market-style incentives and disincentives; (c) introducing a customer orientation coupled with consumer choice and branding; (d) devolving budget functions while maintaining tight control through auditing and oversight; (e) outsourcing labour with casual, temporary staff; and (f) emphasizing greater output performance measures and controls in the name of efficiency and accountability. 
With these fundamental changes we are witnessing the full-scale implementation of audit culture. In fact, audit culture has now crept from being a method of financial verification to a general model or technology of governance that is reshaping almost every aspect of higher education. The sociologist Michael Burawoy (2011) has examined how an overly benchmarked reliance on key performance indicators distorts university practices and likens their effect to oldschool Soviet planning, where tractors were too heavy because their outputs were measured by weight, and glass was too thick because targets were in volume.

The tabulation of our worth as scholars through narrowly conceived, quantifiable metrics that consider, for the most part, only simplistic counts of peer-reviewed publications, impact factor rankings, and research grants - in a dystopian cut-throat higher education version of The Hunger Games - has necessarily given rise to a host of distortions, not least of which is a proportionate growth in "cooked" science and findings. In other cases, yes, it has also contributed to less-than-perfect peer review by overtaxed academics overrun by salami-sliced research reporting where one complete article gets chopped up into three or four publishable units that clog up the entire manuscript review process.

If the academy is ever to escape these negative consequences brought on by a misapplied audit culture, it will only be when we denounce the "game" and cease to allow ourselves to be measured by such narrowly defined outputs in a one-size-fits-all factory model of knowledge creation, dissemination, and accounting.

Whatever the easy stereotype of the life of a scholar, either sequestered away in an ivory tower or perhaps, in reality, more appropriately replaced with the image of hamsters endlessly turning wheels in the audit culture's office blocks, in envisioning the nature of our future home, surely we should seek to repopulate the academy's lighthouse, and once again provide the diverse array of consequential scholarship, innovation, action, and critical public engagement our world so desperately needs. 


\section{References}

Burawoy, M. (2011). Redefining the public university. In J. Holmwood (Ed.), A manifesto for the public university (pp. 27-41). Bloomsbury Academic. doi:10.5040/9781849666459

Cassidy, S. (2014, Nov. 28). University inquiry into Professor Stefan Grimm's death. Independent.Schuessler, J. (2018, Oct. 4). Hoaxers slip breastaurants and dog-park sex into journals. The New York Times. Retrieve from https://www.nytimes.com/2018/10/04/arts/academic-journals-hoax.html

Dominus, S. (2017, Oct. 18). When the revolution came for Amy Cuddy. The New York Times. Retrieve from https://www.nytimes.com/2017/10/18/magazine/when-the-revolutioncame-for-amy-cuddy.html

Grievance Studies affair. (2018). Wikipedia. The free encyclopedia. https://en.wikipedia.org/wiki/Grievance_Studies_affair

Pinker, S. (@sapinker). (2018, Oct. 3). Tweet on Twitter Retrieve from https://twitter.com/sapinker/status/1047446850008219649

Rosenberg, E., \& Wong, H. (2018, Sept. 20). This Ivy League food scientist was a media darling. He just submitted his resignation, the school says. The Washington Post. https://www.washingtonpost.com/health/2018/09/20/this-ivy-league-food-scientist-wasmedia-darling-now-his-studies-are-being$\underline{\text { retracted/? } \text { noredirect }=\text { on\&utm term }=.0995 \mathrm{~d} 8297096}$ 